\title{
PESQUISAS COM CRIANÇAS INDÍGENAS E CAMPO DOS ESTUDOS CULTURAIS: BRICOLAR E EXPERIENCIAR COMO BASE METODOLÓGICA
}

\author{
RESEARCH WITH INDIGENOUS CHILDREN AND THE FIELD OF CULTURAL STUDIES: BRICOLAR AND \\ EXPERIENCING AS A METHODOLOGICAL BASIS
}

\author{
INVESTIGOS CON NIÑOS INDÍGENAS Y CAMPO DE LOS ESTUDIOS CULTURALES: BRICOLAR Y EXPERIENCIAR \\ COMO BASE METODOLÓGICA
}

\author{
ALVES, Rozane Alonso' \\ NASCIMENTO, Adir Casaro2
}

\section{RESUMO}

A proposta deste artigo busca problematizar o uso da bricolagem e do experienciar como base teórico-metodológico no campo das pesquisas com crianças indígenas. Buscando dialogar com as crianças indígenas, as autoras trazem neste excerto, os aspectos teóricos-metodológicos que produziram os dados, e observaram os olhares e as experiências no contexto da bricolagem e da experienciação. Propomos analisar as implicações conceituais e metodológicas que possibilitaram a ampliação da campo empírico, além da abertura ao estar com crianças indígenas e construir com elas possibilidades metodológicas. Apontamos o campo dos Estudos Culturais como campo conceitual que constitui as discussões sobre bricolar e experienciar com crianças indígenas.

Palavras-chave: Crianças Indígenas. Bricolar. Experienciar. Pesquisa. Estudos Culturais.

\section{ABSTRACT}

The main proposal of this paper seeks to problematize the use of bricolage and to experience as a theoretical and methodological basis in the field of research with indigenous children. Trying to dialogue with indigenous children, the authors bring in this excerpt the theoretical and methodological aspects that produced the data, and observed biases and experiences in the context of bricolage and experience. We propose to analyze the conceptual and methodological implications that enabled the expansion of the empirical field, besides the openness to be with indigenous children and to construct with them methodological possibilities. We point the field of Cultural Studies as a conceptual field that constitutes the discussions about bricolar and experiencing. Keywords: Indigenous children. Bricolar. Experiencing. Search. Cultural Studies.

\section{RESUMEN}

La propuesta de este artículo busca problematizar el uso del bricolaje y del experienciar como base teórico-metodológica en el campo de las investigaciones con niños indígenas. Al buscar dialogar con los niños indígenas, las autoras traen en este extracto, los aspectos teóricos-metodológicos que produjeron los datos, y observaron las miradas y las experiencias en el contexto del bricolaje y la experiencia. Proponemos analizar las implicaciones conceptuales y metodológicas que posibilitar la ampliación del campo empírico, además de la apertura al estar con niños indígenas y construir con ellas posibilidades metodológicas. Apuntamos el campo de los Estudios Culturales como campo conceptual que constituye las discusiones sobre bricolar y experimentar con niños indígenas.

Palabras clave: Niños Indígenas. Bricolar. Experiencia. Investigación. Estudios Culturales.

\footnotetext{
1 Instituto Federal Goiano - IFG - Ipameri - Goiás - Brasil

${ }^{2}$ Universidade Católica Dom Bosco - UCDB - Campo Grande - Mato Grosso do Sul - Brasil
} 


\section{PARA INÍCIO DE CONVERSA}

A proposta deste artigo, é descrever como a bricolagem e o experienciar se tornaram base metodológica para a construção de uma tese de doutorado intitulada: Ya Ka na ãra Wanã, movimento indígena e a produção das identidades das crianças Arara-Karo (Pay Gap/RO). Tese que esteve vinculada à Linha de Pesquisa: Diversidade Cultural e Educação Indígena do Programa de PósGraduação Mestrado e Doutorado em Educação da Universidade Católica Dom Bosco (UCDB).

É importante localizar o leitor sobre o contexto desta comunidade indígena antes de iniciar nossas pontuações sobre o objetivo central deste artigo que é descrever as implicações, os deslizes, as articulações e negociações da bricolagem e do experienciar no campo da pesquisa com crianças indígenas.

Sendo assim, a etnia Arara-Karo pode ser considerada uma sociedade que possui pouco mais de 350 pessoas, que falam o tronco linguístico Tupi, sendo da família linguística Tupi Ramarama. $O$ povo Arara-Karo reside na Terra Indígena Igarapé Lourdes no município de Ji-Paraná, no estado de Rondônia - RO, e divide a Terra Indígena com o povo Gavião-Ikolen que antes era do Estado do Mato Grosso. Atualmente o povo Arara-Karo se organiza em três aldeias: a I'Terap, com cerca de 280 indígenas; a Pay Gap, com 76 integrantes; e a Cinco Irmãos, com 17 indígenas.

A aldeia Pay Gap fica a cinquenta quilômetros da cidade de Ji-Paraná, no estado de Rondônia. O principal ponto de chegada é pelo distrito de Nova Colina. Após o distrito, a estrada é de chão. Dos 76 indígenas residentes da Pay Gap, 44 são consideradas crianças (Owen e Nako't). Lembrando que Owen são as crianças pequenas, e Nako't são crianças crescidas, ou seja, que ainda não se casaram e não constituíram seu próprio núcleo familiar. Das 44 crianças, 28 têm entre 4 meses a 11 anos de idade na época da pesquisa.

Contextualizada a comunidade e o povo Arara-Karo, passamos a apresentar o campo teóricometodológico ao qual discutimos e problematizamos o conceito bricolar e experienciar, sendo este, o campo dos Estudos Culturais.

Os Estudos Culturais se apresentam como um campo de investigação que transita nas instabilidades da própria investigação e, ao mesmo tempo, se constitui com espaço de "produção de novos saberes acerca dos modos como processos socioculturais estão implicados na construção de nossas concepções sobre o mundo". (KIRCHOF; WORTMANN; COSTA, 2015, p. 8).

Pensar os métodos e os procedimentos metodológicos de produção de dados como práticas investigativas que devem contextualizar os sujeitos, suas relações, experiências, movimentos, identidades, culturas, negociações, articulações, entre outras questões que se fizerem relevantes a partir do campo empírico, são problematizações presentes nos campos teóricos em tela. É interessante entender que contextualizar não se restringe a descrever um contexto ou uma relação, mas inclui aproximar sujeitos, culturas, e visibilizar as relações dos sujeitos com e sobre seu contexto.

Essa transitoriedade metodológica no pesquisar com crianças indígenas nos permite problematizar os deslizes, os escorregões na escrita, nas leituras, nas pesquisas, nas análises. $O$ 
escorregar, o deslizar ${ }^{3}$ além de criar a possibilidade de viver nas fronteiras ${ }^{4}$, constitui também condições desses sujeitos pesquisadores(as) de olhar as suturas ${ }^{5}$ dos sujeitos com quem se pesquisa, neste caso, as crianças indígenas.

Os Estudos Culturais não se constituem como teorias fixas, rígidas, mas como um campo de articulação, de transgressão, de subversão, uma vez que, em seus campos de investigação, discussão, problematização e análise, atuam sobre contextos e sujeitos múltiplos, e suas verdades são sempre provisórias.

As articulações, as possibilidades teórico-metodológicas, deste campo, permitem a produção de narrativas outras nos discursos sobre os estudos das culturas infantis. Se no âmbito dos discursos constituídos como verdade por meio do eurocentrismo/ocidentalismo sobre a criança e a forma de se viver as infâncias produziam/produzem narrativas homogeneizantes, estereotipadas e generalizantes, as concepções e percepções dos Estudos Culturais provocam o/a pesquisador(a) frente ao campo empírico a negociar com os conceitos que sustentam seus estudos, ele(a) desestabiliza essas narrativas, problematizando-as e constituindo um espaço de discussões outras, sobre as formas de ser das crianças.

Apontamos que tais discussões outras, para além das possibilidades de problematizar as crianças, podem também trazer para este trabalho as traduções, as negociações e as transgressões (BHABHA, 1990; 1998) destas formas de ser criança-sujeito-indígena, vivenciados e experienciados por ela. É sobre essas possibilidades teóricas-metodológicas que passamos a discutir.

\section{BRICOLAR E EXPERIENCIAR: BASES METODOLÓGICAS E PROCEDIMENTOS NO PESQUISAR COM CRIANÇAS INDÍGENAS}

Bricolagem e experiência foram bases conceituais e metodológicas que nos guiaram durante a produção de dados da tese supramencionada. Guiaram-nos, mas não nos limitou; guiaram-nos, mas não cercaram nossos passos; guiaram-nos e se tornaram base deslizante, movediça no fazer metodológico.

Foi diante dos deslizes do experienciar, vivenciar e bricolar que a empiria foi tomando corpo. A partir do estar com as crianças novas indagações foram sendo tecidas, questionadas, levantando

\footnotetext{
${ }^{3}$ Hall (2005) conceitua deslizar a partir do campo da linguagem, propondo que não há um significado nas/para as "coisas", as "coisas" são contingenciais, movediças, produzidas a partir do tempo, do momento, do uso dos discursos como estratégia temporal.

${ }^{4}$ Viver nas fronteiras ou entre-fronteiras não se constitui como a demarcação/cercamento de um espaço, contexto, mas como a transposição de sujeitos e culturas que vivem entre-lugares (local intersticial). Para Bhabha (1998, p. 24), "fronteira se torna o lugar a partir do qual algo começa a se fazer presente [...] ponte que reúne enquanto passagem que atravessa".

5 "O fato de que projetamos a 'nós próprios' nessas identidades culturais, ao mesmo tempo que internalizamos seus significados e valores, tornando-os 'parte de nós' contribui para alinhar nossos sentimentos subjetivos com os lugares objetivos que ocupamos no mundo social e cultural. A identidade, então, costura (ou, para usar uma metáfora médica, 'sutura') o sujeito à estrutura. Estabiliza tanto os sujeitos quanto os mundos culturais que eles habitam, tornando ambos reciprocamente mais unificados e predizíveis". (HALL, 2005, p. 12).
} 
novas problemáticas, indagando as respostas, resinificando as perguntas. Mas esse movimento leve e complexo não descaracteriza as narrativas, os olhares, os gestos, os risos, os silêncios, os desenhos, as fotografias que também fazem/fizeram parte do campo metodológico. Estar junto às crianças se constituiu como o principal procedimento para a produção de dados. Analisar os dados nos fez durante todo esse processo estremecer, isso porque criamos pensamentos sobre o que vivenciamos, sobre aquilo que nos tocou. Fomos produzidas, ao tempo que também produzimos algo para as crianças.

Pensar sobre isso, colocar em destaque as palavras que escolhemos utilizar durante a construção deste excerto nos fez perceber que as estratégias metodológicas não são em si estruturas para trazer à tona as narrativas das crianças. São, neste caso, possibilidades para que pudéssemos participar do cotidiano da comunidade e estar atenta às suas vozes e olhares.

A experiência, ao ser tocada, ter o corpo transpassado por outros corpos, nos fez talvez perceber que a experiência é "algo que não sou eu, um acontecimento, passa. Mas supõe também, [...] que algo me passa. Não que passe ante mim, ou frente a mim, mas a mim, quer dizer, em mim. A experiência supõe um acontecimento exterior a mim. Mas o lugar da experiência sou eu". (LARROSA, 2011, p. 6).

As experiências das crianças se efetivam nas relações cotidianas com a comunidade, com o espaço e o contexto da aldeia. As brincadeiras se juntam aos mitos e às histórias do povo Arara. As crianças indígenas brincam, transitam entre as relações que estabelecem com os rituais que elas vivenciam e presenciam em sua cotidianidade. As crianças indígenas Arara criam aprendizagens por meio das brincadeiras, das experiências rituais das histórias contadas pelo pajé que só são possíveis de serem aprendidas, capturadas pela sua fala, pois ele é quem conhece, quem vivenciou os rituais e os mitos e se apropriou destas vivências e, agora, compartilha com os mais jovens a história do seu povo.

A "experiência supõe, portanto, uma saída de si para outra coisa, um passo para outra coisa" (LARROSA, 2011, p. 8), atravessar e ser atravessado, experiência demanda uma articulação entre negar e afirmar, perceber e não enxergar, estar e não permanecer.

Ao experienciar o cotidiano das crianças, fomos percebendo os modos como elas lidam com o narrar, ou seja, quais estratégias utilizam para falar com o outro não indígena. Observar as brincadeiras, suas circulações pelos trieiros da comunidade, a maneira como ouvem os mais velhos, como questionam o que ouvem. Essas experiências foram guiando meus olhares e possibilitando a ressignificação dos instrumentos metodológicos que, de algum modo, eu já havia pré-definido.

Experiência. Foi a partir deste conceito que propomos estar com elas sem impor uma presença de pesquisadora, mas como alguém que aprende. Participar apenas daquilo que nos convidavam, ser sincera sobre nossa estadia, nos permitir (aquilo que nosso corpo pudesse experienciar) participar do cotidiano delas sempre que elas permitissem.

Devemos também buscar neste excerto "explorar o que a palavra experiência nos permite pensar, o que a palavra experiência nos permite dizer, e o que a palavra experiência nos permite fazer 
no campo pedagógico". (LARROSA, 2015, p. 38). A experiência é um espaço intersticial onde ocorrem encontros, desencontros, onde nos desfazemos, refazemos, nos fazemos, onde somos sujeitos que produzem e somos produzidos nas relações que estabelecemos com o outro. A experiência "determina a forma e a substância não só do mundo, mas também de nós mesmos, de nosso pensamento e de nossa experiência". (LARROSA, 2015, p. 58).

O pesquisador/a deve também ser cautelosa ao propor a experiência como uma das chaves que abrem caminhos no fazer metodológico. Cautelosa, pois devemos desconfiar "de la experiencia cuando se trata de hacer uso de la razón, cuando se trata de pensar y de hablar y de actuar racionalmente. En el origen de nuestras formas dominantes de racionalidad, el saber está en otro lugar que en la experiência”6. (LARROSA, 2015, p. 58).

Cautelosa até mesmo para pensar sobre os povos indígenas, sobre as crianças e seus modos de ser. Desmistificar a infância na lógica de organização e de ser do povo, neste caso, Arara-Karo, pensando na produção desses sujeitos a partir de sua tradição, das traduções, das negociações, das articulações, das ressignificações vivenciadas por estes sujeitos. Tornamo-nos (um processo em construção, constante, movediço) um sujeito que mesmo sabendo, não temos informações suficientes para narrar uma história, um modo de ser, uma cultura. Tornamo-nos um sujeito alheio que busca experienciar a história de um povo, sua cultura, seus modos de ser, sua lógica de organização. Tornamo-nos "esse sujeito que não é o sujeito da informação, da opinião, do trabalho, que não é o sujeito do saber, do julgar, do fazer, do poder, do querer". (LARROSA, 2002, p. 24).

Circular com as crianças, participar da rotina da comunidade fizeram com que nosso corpo de pesquisadoras fossem rasurados. Pensar as fotografias como um recurso, uma extensão do olhar da criança se tornou possível quando experienciamos com elas a curiosidade, quando percebemos o modo como elas lidam com as câmeras dos celulares de seus familiares.

Observando elas e as câmeras de celulares, atentamo-nos ao fato de elas não fazerem pose para fotos, mas de irem registrando o momento, as brincadeiras, as conversas. É por meio desse acontecimento, de estar com elas e experienciar seu cotidiano que propusemos o uso de fotografias como possibilidade de narrar o que pensam as crianças sobre o movimento indígena (foco da pesquisa que se tornou tese) no contexto da Pay Gap .

A experiência não como tática de descrição, mas como recurso de bricolagem, que colocou sob rasura nossas estratégias de produção de dados. Estar com as crianças e a comunidade exigiu rasurar e suturar minhas memórias sobre a infância. Ao nos colocarem (pois foi isso que o campo empírico fez conosco) nesse jogo de rememorar, fomos dialogando com as crianças a partir dessa trajetória de infância. Compartilhar as brincadeiras que faziamos e aprender novas maneiras de brincar nos possibilitou perceber o quanto a memória é afetiva.

\footnotetext{
${ }^{6}$ de acordo com a questão de saber como se trata de um pedido de pagamento, quando se trata de pensar e de falar e de atuar racionalmente. Em el origen de nossas formas dominantes de racionalidade, o saber está em outro lugar na experiência (tradução da autora).
} 
Afetada por essas memórias que foram trazidas em nós por meio das experiências que tivemos com as crianças é que refazemos a maneira como pensemos as entrevistas com as crianças, pois percebemos que suas narrativas são coletivas, fazem parte dos modos de ser das crianças.

Nessa articulação entre as memórias e os modos de ser das crianças, as entrevistas dos mais velhos não se tornaram apenas parte de um objetivo de tese: descrever o processo de colonização... Mas de pensar como ouvir essas histórias as quais eu gravaria poderia também se tornar uma estratégia para perceber as identidades das crianças.

A ideia do experimentar a si e ao outro por intermédio das narrativas históricas é pontuada aqui como uma ferramenta de "autotransparência" e não como uma estrutura que faz o sujeito se dizer a partir de um lugar já dado, imposto. Pelo contrário, é pensar essa ferramenta como um mecanismo que permite a este indivíduo analisar, rever as estruturas postas a ele por meio de práticas sociais de ordenamento. De poder recontar-se de outro modo. Caso contrário, vamos afirmar que na sociedade há sempre uma história de reprodução impossibilitada de ser contada de formas diferentes, por pessoas variadas, de lugares e em lugares totalmente distintos, ou até mesmo pertencentes ao mesmo espaço, mas com experiências de maneiras díspares.

Estas formas de ver o outro estariam, talvez, dentro do contexto de participação junto ao movimento indígena, ou de tantos outros processos dos quais estas crianças fazem parte. É dentro desta perspectiva enunciativa que as crianças indígenas estão se dizendo indígenas, estão se constituindo como indígenas, sobre suas identidades e seus modos de ser.

Ao pesquisar nos colocando a pensar, a vivenciar, fomos nos atrevendo a olhar com outros olhos aquilo que já conhecia e, ao mesmo tempo, nos deixar ser surpreendidas pelo conhecido, tornando-o desconhecido e inquieto para nós.

A experiência é contingencial, movediça. A experiência é acontecimento entre sujeitos, contextos, lugares, culturas, pensamentos. A experiência é um caminho com idas e vindas, retornos. A experiência demanda sensibilidade.

Utilizar a experiência como procedimento metodológico e articular com as discussões e apropriações do conceito de bricolagem colocou em xeque algumas definições de pesquisas com crianças que vinhamos desenvolvendo.

Experiência e bricolagem foram elaborando cartografias afetivas nos modos como fomos vivenciando o campo empírico. Cartografamos por meio das nossas memórias, do estar com as crianças e a comunidade, de ouvir as crianças indígenas. Cartografar "é, fundamentalmente, o grau de abertura para a vida que cada um se permite a cada momento". (ROLINK, 1989, p. 68).

Nossas memórias circularam em meio às experiências de pesquisa já havíamos realizado, mas também nos fez problematizar os discursos que produzimos a partir de nosso modo de fazer pesquisa. Por meio delas bricolamos também nossas lembranças, pois fomos percebendo nessas suturas as nossas identidades e as ressignificações que sofremos ao longo da nossa vida acadêmica. 
A bricolagem fornece um alento nas tormentas da pesquisa. Bricolar se tornou um porto, um lugar de reflexão, de problematização, de novas possibilidades, de novos olhares e olhares outros. $O$ que estamos denominando de bricolagem (conceito que não é meu, mas cada apropriação nos constitui enquanto pesquisadora) tem suporte teórico-metodológico nos Estudos Culturais.

Bricolagem são rasuras metodológicas que nos permitiram desviar de caminhos fixos (muitas vezes construídos por mim mesma), de olhares naturalizados, cristalizados sobre as crianças indígenas.

"Articular Saberes e bricolar metodologias" (PARAíSO, 2012, p. 33) nos permitiu perceber as barreiras de nossas opções pré-estabelecidas para produzir dados como estratégias, como possibilidades de novos procedimentos metodológicos junto às crianças indígenas. Bricolar também sobre os olhares das crianças. Como elas percebiam nossas estratégias, como respondiam ou silenciavam, isso tudo apontava caminhos que precisaram ser percorridos. Esses novos caminhos eram muitas vezes tortuosos, pois fugiam daquilo que haviamos estabelecido.

É preciso estar permanentemente à espreita dos silêncios, das falas, dos olhares, dos gestos para experimentarmos novas possibilidades no fazer metodológico. Bricolar exige rigorosidade, vigilância, experimentação, articulação, interrogações, problematizações, desnaturalização e desconstrução de procedimentos arraigados naquilo que pensamos saber sobre o que pesquisamos.

Foi preciso interrogar sobre aquilo que conheciamos, recompor os olhares sobre o que já foi dito e escrito sobre as crianças, estabelecer novas relações, construir novos enunciados, "compor uma outra imagem de pensamento" (PARAíSO, 2012, p. 37) para a investigação. Eis que a bricolagem nos recebe como um barco à deriva que avista um porto não fixo, fechado, mas polido, deslizante e, ao mesmo tempo, rigoroso. Entender que

[...] pesquisa tem tempos próprios: um tempo para perder-se entre grandes planícies, repletas de cheiros, sabores, cores atraentes, que produzem uma vontade de saber, uma vontade de experimentar muitos daqueles modos possíveis de leitura e de escrita; um tempo para situar-se entre perspectivas, outros tempos para fazer escolhas e seguir viagem. A pesquisa tem um ir e vir continuamente reinventado, passamos longos momentos articulando noções, aproximando autores, exultando com pequenos "achados", mas também deixando de lado aquilo que, antes, parecia tão precioso e inovador. (BONIN, 2007, p. 55).

Tempos que precisam ser respeitados. As crianças não estavam dispostas a ficar respondendo a questões como em interrogatórios, por isso utilizar os espaços cotidianos delas para ouvir suas conversar com seus pares e ir me abrindo para escutá-las, conversando sobre diferentes coisas em distintas línguas - materna e língua portuguesa, esperar a tradução delas no seu tempo, quando elas queriam traduzir para que pudessemos entender e participar da discussão. Ouvir muito mais que falar, foi assim que pudemos nos aproximar delas.

Elas conversam de diferentes maneiras, apenas rindo, desenhando na areia, brincando, olhando os pássaros e fazendo o som de seus cantos em forma de assovio. (DIÁRIO DE CAMPO, janeiro de 2017). Estar disposto ao silêncio e utilizá-lo como parte da pesquisa é assustador, ao menos 
foi para nós. Queríamos tanto ouvi-las trazer suas narrativas, anotá-las no diário de campo, gravar, ter dados. Escrever a tese. Para alguém que fala muito e rapidamente, o silêncio pode ser tortuoso. Por isso, experienciar com elas a calmaria foi aprendizagem. Bricolamos também nossos modos de ser nas estratégias metodológicas.

A bricolagem exige de nós pesquisadores e pesquisadoras desterritolizar-nos de nós mesmos/as para reconstruir novos territórios (PARAÍSO, 2012), inventar novas possibilidades sem nos abandonarmos. Bricolar exige viver nas fronteiras, estabelecer relações de sutura com os sujeitos, contextos e experiências inseridos na pesquisa, no fazer metodológico. Viver nas fronteiras ou entre fronteiras não se constitui como a demarcação/cercamento de um espaço, contexto, mas como a transposição de sujeitos e culturas que vivem entre-lugares (local intersticial). Para Bhabha (1998, p. 24), "fronteira se torna o lugar a partir do qual algo começa a se fazer presente [...] ponte que reúne enquanto passagem que atravessa".

Essa problematização de Bhabha (1998) sustenta, mesmo que provisoriamente, o olhar que vinhamos estabelecendo sobre a bricolagem. Um suporte que permite me mover nas fronteiras metodológicas sem me cercar de procedimentos acertativos. Ao mesmo tempo, me permite utilizar recursos já conhecidos e inserir novos à medida que os sujeitos participantes da pesquisa vão me dando pistas.

Essas pistas só puderam ser percebidas quando nos despimos das nossas metodologias e procedimentos estabelecidos. Nem sempre, ou quase sempre, conseguidos nos desfazer, nos despir daquilo que estabelecemos como recurso procedimental correto, certeiro. A tarefa se faz difícil nos caminhos metodológicos percorridos, mas se torna prazerosa quando nos vemos sujeitos atuantes, experienciando com, neste caso as crianças, acontecimentos cotidianos que acabam se tornando parte de nós (de mim), das minhas vivências.

Olhar as suturas se constitui pelo fato de que projetamos a "nós próprios" nessas identidades culturais, ao mesmo tempo em que internalizamos seus significados e valores. Tornando-os "parte de nós" contribui para alinhar nossos sentimentos subjetivos com os lugares objetivos que ocupamos no mundo social e cultural. "A identidade, então, costura (ou, para usar uma metáfora médica, 'sutura') o sujeito à estrutura. Estabiliza tanto os sujeitos quanto os mundos culturais que eles habitam, tornando ambos reciprocamente mais unificados e predizíveis". (HALL, 2005, p. 12).

Ao retomar Bhabha (1998) sobre a questão da ponte que atravessa quando falamos em viver nas fronteiras metodológicas e identitárias, referimo-nos àquilo que me afetou, me deslocou, exigindo um "esforço de invenção e ressignificação" (PARAísO, 2012, p. 23) constantes.

Estar atento ao campo empírico é o que permite o uso da bricolagem no contexto metodológico. Isso não significa que não há o rigor nas novas possibilidades que a experiência de estar com as crianças produziu. Pelo contrário, isso se tornou mais rigoroso pelo diálogo estabelecido a partir da cotidianidade e de seus modos de ser. 
$\mathrm{Na}$ perspectiva teórico-metodológica em que nos inserimos, inexiste um lugar fixo para as pesquisas acadêmicas. Tampouco existe o afastamento do rigor metodológico que o campo exige. Pelo contrário, estamos (ou estamos falando quando nos referimos destes campos conceituais) nos colocando no lugar do aprender com o outro, incluindo os procedimentos metodológicos. Os silêncios, os olhares, os risos, os gestos são recursos importantes para a bricolagem. Mover, bricolar, pesquisar a diferença exige o cuidado de estar atento a estes recursos.

"Pesquisar é uma aventura" (COSTA, 2007, p. 147), devemos estar atentos a nossas intuições, inquietações, as "pistas, suspeitas e dúvidas merecem ser objeto de atenção, e não deveriam ser descartadas sem antes perscrutar cuidadosamente várias possibilidades de conectá-las com aquilo que se deseja pesquisar". (COSTA, 2007, p. 147).

A vontade de ouvir as crianças falarem sobre o movimento indígena, de participar de várias reuniões na comunidade, tornou-se um empecilho para perceber nelas outros modos de ser que se articulam na produção de suas identidades. Dar uma chance ao falar necessita de nós a possibilidade de ouvir, de escutar com sensibilidade. Estar atento a "outras imagens, outras letras, outras línguas, outros acordes, outros batuques e transes, outros colares e penas". (ARANTES, 2011, p. 93). Escutar "é se deixar afetar pelos ruídos e barulhos do mundo". (ARANTES, 2011, p. 94).

Afetar exige o desprendimento de que a pesquisa ocorre de forma linear. A este respeito, Lazzarotto e Carvalho (2012, p. 27) escrevem que

\footnotetext{
Não precisamos mais temer o processo de estarmos afetados pelo acontecimento no ato de pesquisar, pois o que antes era dado como ponto fraco do pesquisador, agora marca uma condição indispensável do processo de pesquisar: a capacidade de afetar e afetar-se para que se criem os modos de expressar os sentidos de uma pesquisa.
}

Afetados pelos olhares, pelos gestos é que nos apropriamos da bricolagem como um recurso, um procedimento, uma possibilidade outra de se fazer pesquisa com crianças indígenas Arara-Karo. Ser afetado no fazer metodológico exige um devir (DELEUZE; GUATARRI, 2004) como uma potência durante o percurso, durante as tensões, durante o balançar de nossos fazeres metodológicos, das nossas experimentações, experienciações, vivências e aprendizados.

Por ser afetada é que fomos propondo novas brincadeiras como possibilidade de criar um ambiente agradável para que as crianças pudessem narrar as suas afetividades com o movimento indígena. O brincar para ela são expressões dos modos como elas lidam com o contexto, com a cultura e suas ressignificações. Utilizar-se desse recurso como estratégia de perceber como elas lidam com os espaços da comunidade e os experienciam em suas circularidades me proporcionou novos olhares sobre como suas identidades vão sendo produzidas, atreladas à cosmovisão e à pedagogia indígena.

"Quando afetados pelas audições e visões, gostos e cheiros, toques de vida que nos forçam a pesquisar na historicidade de um tempo que acontece" (LAZZAROTTO; CARVALHO, 2012, p. 26-27), vamos percebendo que as problematizações que fizemos e fomos afetada a fazer "são feitas de vida". (LAZZAROTTO; CARVALHO, 2012, p. 26-27). É diante destas feituras que fomos nos propondo a ouvir 
as histórias dos mais velhos, os saberes que circulam com as crianças, as circularidades produzidas pelas crianças, de sentar-me com eles, de brincar com elas, de ser pesquisadora e, ao mesmo tempo, não ser.

São as afetividades que nos movimentaram, que nos colocaram na pesquisa como quem quer muito mais aprender do que ensinar, como quem muito mais quer se refazer e reinventar que estabelecer e reafirmar. Eis novamente que a bricolagem vai se constituindo como modos específicos e desprendidos de pesquisar a diferença, as culturas, os sujeitos, os modos de ser, de ver, de vivenciar, de experienciar, neste caso, meus modos, meus olhares, meus fazeres metodológicos.

Pesquisar foi se tornando um processo de criação, de reinvenção, de rigorosidade. Pesquisar se constituiu como provisoriedade, de conhecimentos, dos próprios objetivos estabelecidos a priori, da história, da colonização não contada e, ao mesmo tempo, reafirmada. A bricolagem se tornou uma arena de significados. (SILVEIRA, 2007).

A bricolagem exigiu coletar informações por meio de diferentes procedimentos metodológicos, sendo eles a etnografia numa perspectiva pós, a cartografia, os desenhos, as fotografias, as brincadeiras, as entrevistas, os grupos de conversa, as circularidades, os distanciamentos e os silenciamentos. Para isso, precisamos encontrar pontos nodais (BHABHA, 1998) entre esses elementos, entre esses procedimentos. Precisei anotar, perguntar, observar, me interrogar, articular, desnaturalizar, desconstruir, caminhar, correr, enfim, estar, experienciar.

Ao final, precisamos remontar, bricolar até mesmo os resultados produzidos. Foi necessário também refazer as leituras dos campos conceituais, discutir e problematizar suas articulações, aproximações e distanciamentos, manuseando o fazer investigativo, como aponta Paraíso (2012) também sob o ponto de vista das questões teóricas.

Atrelado aos recursos metodológicos, retomar as narrativas produzidas nesses procedimentos exigiu também rever os campos teóricos em que nos apoiávamos metodologicamente. Ao revisitar os desenhos, percebemos que os traços e as cores utilizadas pelas crianças não davam conta das discussões delas sobre o que desenharam. Para isso, as descrições desses dados deveriam se ater às narrativas das crianças sobre o que foi traçado nas folhas, sobre suas percepções, seus sentimentos, sobre o modo como elas lidam com a natureza, com a cosmologia, com a comunidade, com o território, com o ser criança indígena - questões que aparecem em seus desenhos.

As fotografias exigiram o mesmo cuidado, pois, ao registrarem momentos e espaços, elas o faziam como extensão de suas percepções sobre seus ser. A fotografia não poderia ser utilizada para narrar o que elas entendem por onde o movimento indígena transita no contexto da Pay Gap, mas também como a própria comunidade lida com espaços institucionalizados.

Ao construir as metodologias empregadas na pesquisa, acabamos por buscar novos textos, diferentes textos, aportes, bases que pudessem dar conta dos procedimentos metodológicos que me acolheram e que foram inspirados pelas crianças indígenas. 
Ao revistar os dados produzidos, deslocamos teorias, objetivos, e, a nós mesmas. Antes de dizer que analisamos, que observamos e que descrevemos os resultados, buscamos perceber os caminhos que percorremos e quais ferramentas nos acompanharam e o porquê dessas escolhas metodológicas.

Ao longo da pesquisa, é precisa pontuar os deslocamentos, rasuras e suturas sobre as identidades das crianças que são produzidas por elas, pelo contexto, pelas culturas, pelas subjetividades, pelos seus modos de organização, modos de ser, entre tantos artefatos, linguagens e discursos que envolvem seu povo, sua cultura, do que afirmações de como suas identidades são produzidas. Talvez aqui se encontre o ponto nodal ao trabalhar a bricolagem e o experienciar na pesquisa com crianças.

Mais do que falar, narrar e descrever a produção das identidades das crianças Arara-Karo frente à participação delas no movimento indígena, narro as experiências de alguém que se propõe a aprender sobre esse povo, sobre diferenças, sobre culturas, sobre fazer pesquisa. Quando nos damos conta de que não podemos coletá-los, mas participar das experiências e vivências dos contextos que nos propomos a pesquisar, percebemos que estamos, talvez, "a espreita de uma inspiração", aceitando "experimentar, fazer bricolagens e transformar o recebido". (PARAíso, 2012, p. 33).

Vamos, então, deslocando nossos olhares, buscando estar atentos aos não ditos durante a pesquisa. Para sermos interpelados, devemos nos despir, nos colocar, nos posicionarmos no jogo da experimentação. Para experimentar, é preciso vestir-se de não senso, deixar o método, a explicação e a interpretação desamparados para que, no ato de produzir os dados, possamos acolher os afetos. Isso porque, para experimentar, não basta apenas entregar-se à experiência, é preciso construir também um modo de permanecer no processo, na pesquisa, que nos solicita intervenção, ou melhor, intervenções. (LAZZAROTTO, 2012).

O exercício da rigorosidade deve constantemente nos acompanhar. Para que uma pesquisa tenha seu caráter crítico e problematizante, ela deve, primeiramente, ser rigorosa, criteriosa, articulada e estar sempre afetada, rasurada, abrindo espaço para novos questionamentos.

Produzir dados, entendendo que "produzir é o encadeamento de práticas corporificadas material ou afetivamente. Produzir é afetar: propiciar um sentimento, criar um objeto, construir um desejo, fazer um movimento, construir campos de possibilidades". (SCHEINVAR, 2012, p. 197).

Os modos de ser, os modos ser afetados são produções metodológicas constituídas no acontecimento, nas vivências e experiências. Produzir são rupturas atravessadas de sentidos múltiplos construídos tanto pelo pesquisador, com seu olhar, sua sensibilidade, quanto pelos sujeitos participantes, com seus modos de acolher a pesquisa, de afetar o pesquisador(a) e serem afetadas, as fragilidades, as rotinas, as resistências, as receptividades.

Produzir dados demanda sempre relações, infinitas formas de se relacionar. Produzir dados demanda atravessamentos de saberes, de sujeitos, de olhares. Produzir dados é criação, recriação, movimentos inconclusos. Produzir dados demanda um diálogo constante entre sujeitos-pesquisa- 
pesquisador(a). Produzir dados demanda do pesquisador(a) reinventar-se, criar desvios, perceber os desvios, desconfiar dos desvios. Produzir dados se insere no jogo da diferença.

A "única tranquilidade que o pesquisador pode ter nesse sentido se refere ao fato de suas construções the permitirem novas construções e novas articulações entre elas capazes de aumentar a sensibilidade [...]". (REY, 2005, p. 7). É um colocar-se sempre que possível no interstício entre os procedimentos metodológicos utilizados para tentar perceber aquilo que escapou, que se escondeu, que silenciou. É estar atento para poder enxergar as possibilidades, ser sensível para poder propor articulações. É permitir com que os colaboradores(as) sejam também sujeitos pesquisadores(as) no ato de pesquisar sobre si mesmo, suas culturas, identidades, subjetividades, histórias, contextos.

Para se colocar nesses interstícios, precisamos pensar a pesquisa como passeio, com "planícies repletas de cheiros, sabores, cores atraentes, que produzem uma vontade de saber, uma vontade de experimentar" (BONIN, 2007, p. 54). "A pesquisa tem um ir e vir continuamente reinventado, passamos longos momentos articulando noções, aproximando autores, exultando com pequenos 'achados', mas também deixando de lado aquilo que, antes, parecia tão precioso e inovador". (BONIN, 2007, p. 55).

Para criar esses procedimentos, precisamos negociar com as crianças também os interstícios metodológicos. Negociar não como pegadas que devesse seguir, trilhar, mas buscando perceber sempre "os novos e inusitados caminhos a percorrer". (BACKES, 2005, p. 56).

Precisamos ainda negociar muitos posicionamentos, olhares, gestos. Pensar nas relações que produzimos com as crianças indígenas como efeitos, afetos foram colocados em suspenso. Suspender o que sabia faz parte de uma pesquisa ou do pesquisador que se diz trabalhar com a complexidade da bricolagem.

Bricolar como negociação, como tradução é também uma "maneira de imitar, mas num sentido traiçoeiro e deslocante - o de imitar um original de tal modo que a sua prioridade não é forçada e sim, pelo fato de ele poder ser simulado, reproduzido, transferido, transformado, tornado um simulacro e assim por diante". (BHABHA, 1998, p. 36).

As participações reinventivas presentes no que estamos chamando de procedimentos metodológicos ao longo deste trabalho foram frutos das relações sociais entre pesquisadoras e as crianças, que nos autorizaram montar tais procedimentos, produzindo uma performatividade metodológica.

Ousando chamar a bricolagem como uma tradução no fazer / construir / elaborar / montar / reinventar / ressignificar da pesquisa, fazemos-a pela percepção que vamos construindo a partir da articulação entre estes conceitos. Bicolagem pode ser também a tradução como "natureza performativa da comunicação cultural" (BHABHA, 1998, p. 313) sendo que "o signo da tradução conta, ou 'canta', continuamente os diferentes tempos e espaços entre a autoridade cultural e suas práticas performativas". (BHABHA, 1998, p. 313). 
O processo de construção, elaboração, montagem e organização dos procedimentos metodológicos são produções de artefatos culturais (teoria também se constitui como artefato cultural, a construção metodológica de um trabalho acaba se constituindo também como teoria) que rearticulam elementos enunciativos, como um trabalho argumentativo, indutivo/induzido, descritivo, percebido, experienciado, vivenciado e rigoroso. Quanto mais leio, mais me convenço de que algo falta, fechamento que necessita estar aberto.

Contingências históricas marcam os sujeitos, essas marcas influenciam a percepção do sujeitopesquisador sobre a investigação que pretende desenvolver. Somos influenciados por nossas experiências, não como sujeitos fixos, imutáveis, inscritos em histórias finitas que não possam ser recontadas, ou ainda, continuadas. Pesquisar, pensar os procedimentos metodológicos envolve também relembrar quais métodos fomos formados para pensar como instrumento de "coletar" os dados.

Enquanto pesquisadoras, fomos colocadas sob rasura, questionaram o que sabíamos sobre o mundo, sobre seu povo, sobre pesquisar com crianças indígenas, sobre o conceito de infância para as comunidades indígenas, sobre a bagagem (de mão) que carregava sobre conhecimento científico. Fomos questionada sobres como pensamos saber e conhecimento. Todas essas problemáticas nos fizeram pensar as propostas metodológicas que exploramos durante a produção de dados. Fizeramnos pensar "onde começa o processo da bricolagem"? (BERRY, 2007, p. 127).

Fomos percebendo que estas questões começam quando entendemos que a bricolagem não se coloca como um conceito ou ciência que busca explicar e determinar como os/e quais procedimentos devem ser utilizados para se constituir como uma pesquisa bricoleur. (KINCHELOE, 2007). Não se explica o mundo, mas nossa relação com o mundo, como afetamos e somos afetados, como percebemos e somos percebidos no contexto em que pesquisamos, no caso, que pesquiso.

E como percebemos e fomos afetadas no tempo em que pesquisamos com as crianças indígena é o que descrevemos e buscamos problematizar neste artigo, propondo um apresentação de nossas experiências e vivências com o fazer metodológico, no que se refere pesquisar com crianças indígenas.

\section{CONSIDERAÇÕES FINAIS}

Negociar com as crianças os caminhos, os instrumentos e procedimentos metodológicos permitem uma fluidez naquilo que propomos ser nosso objetivo de pesquisa com os olhares das crianças sobre este mesmo objetivo. Negociar com elas, aprender com elas, são possbilidades empíricas que permitem as rasuras e suturas de uma pesquisa com crianças.

Esses foram impactos que nos fizeram movimentar a maneira como, até o momento, pensavamos e organizavamos a produção dos dados. Precisemos caminhar com elas, ouvi-las mais, nos sensibilizar com os modos como olham e experienciam o contexto. Precisamos aprender. 
Aprendendo, tivemos de perceber o seu movimentar no contexto de sua cultura, cosmologia e pedagogia indígena. Foram essas percepções que nos permite apresentar em formato de texto acadêmico a produção dos modos de ser crianças indígenas, suas atuações, organizações, estratégias, movimentações como sujeitos-crianças atuantes no contexto de suas comunidades.

Identidades sendo construídas, sendo articuladas e negociadas constantemente, e pela circularidade das crianças que percebemos suas aprendizagens. A circularidade está atrelada à cosmologia indígena. Ao circular, elas percebem as espiritualidades, o território, cultura. A bricolagem e o experinciar nos permitiu observar a produção de seus modos de ser por meio da circularidade como processos de negociação e articulação que envolvem os modos de ser criança indígena e cultura de seu povo.

\section{REFERÊNCIAS}

1. ARANTES, E. M. M. Rostos de crianças no Brasil. In: RIZZINI, I; PILOTTI, (orgs.). A Arte de governar crianças: a história das políticas sociais, da legislação e da assistência à infância no Brasil. São Paulo: Cortez, 2011, p. 153-202.

2. BACKES, José Licínio. A negociação das identidades/diferenças no espaço escolar. $2005.304 \mathrm{f}$. tese (Doutorado em Educação) Centro de ciências Humanas. Universidade do Vale do Rio dos Sinos - UNISINOS. São Leopoldo, Rio Grande do Sul, 2005.

3. BERRY, Katheen. Estruturas da bricolagem e da complexidade. In: KINCHELOE, Joe L; BERRY, Katheen. Pesquisa em educação: conceituando a bricolagem. Porto Alegre: Artmed, 2007.

4. BHABHA, Homi K. O local da cultura. Belo Horizonte: Ed. UFMG, 1998.

5. BONIN, lara Tatiana. E por falar em povos indígenas: quais narrativas contam em práticas pedagógicas? 2007. Tese (Doutorado em Educação) - Universidade Federal do Rio Grande do Sul - UFRGS, Porto Alegre, 2007.

6. COSTA, Marisa Vorraber. Pesquisa- ação, pesquisa participativa e política cultural da identidade. In: COSTA, Marisa Vorraber. Caminhos investigativos II: outros modelos de fazer pesquisa em educação. Rio de Janeiro: Lamparina, 2007. 
7. DELEUZE, G; GUATARRI, F. Mil platôs V. 4: Devir-intenso, devir-animal, devir-imperceptivel. São Paulo: Editora 34, 2004.

8. HALL, Stuart. A identidade cultural na pós-modernidade. 10. ed. Tradução de Tomaz Tadeu da Silva. Rio de Janeiro: DP\&A, 2005.

9. IBGE. Os indígenas no Censo Demográfico 2010. Brasília, 2010. Disponível em: <http://www.ibge.gov.br/indigenas/indigena_censo2010.pdf>. Acesso em: 3 dez. 2016.

10. KINCHELOE, Joe L. Redefinindo o rigor e a complexidade em pesquisa. In: KINCHELOE, Joe L; BERRY, Katheen. Pesquisa em educação: conceituando a bricolagem. Porto Alegre: Artmed, 2007.

11. KIRCHOF, E. R et al. Apontamentos à guisa de introdução. In: KIRCHOF, Edgar Roberto; WORTMANN, Maria Lúcia; COSTA, Marisa Vorraber (orgs.). Estudos culturais e educação: contigências, articulações, aventuras, dispersões. Canoas: Ulbra, 2015.

12. LARROSA, Jorge. Notas sobre a experiência e o saber de experiência. Revista Brasileira de Educação, n. 19, Jan/Fev/Mar/Abr. 2002. Tecnologias do eu e educação. In: SILVA, Tomaz Tadeu da. (org.) O sujeito da educação: estudos foucaultianos. 12. ed. Petrópolis, RJ: Vozes, 2011. Tremores: escritos sobre experiência. Belo Horizonte: Autêntica, 2015.

15. LAZZAROTO, G. D. R. Experimentar. In: FONSECA, T. M. G.; NASCIMENTO, M. L.; MARASCHIN, C. Pesquisar na diferença: um abecedário. Porto Alegre: Sulina, 2012. ; CARVALHO, J. D. A. In: FONSECA, T. M. G.; NASCIMENTO, M. L.; MARASCHIN, C. Pesquisar na diferença: um abecedário. Porto Alegre: Sulina, 2012.

17. PARAÍSO, Marlucy Alves. Metodologias de pesquisas pós-críticas em educação e currículo: trajetórias, pressupostos, procedimentose estratégias analíticas. In: MEYER, Dagmar Estermann; 
PARAíSO, Marlucy Alves (orgs.). Metodologias de pesquisa pós-crítica em educação. Belo Horizonte: Mazza Edições, 2012.

18. REY, Fernando González. Pesquisa Qualitativa e Subjetividades: os processos de construção da informação. São Paulo: Pioneira, 2005.

19. ROLNIK, Suely. Cartografia sentimental: transformações contemporâneas do desejo. São Paulo: Estadão liberdade, 1989.

20. SAID, Edward W. Cultura e imperialismo. Tradução Denise Bottmann. São Paulo: companhia das Letras, 2011.

21. SCHEINVAR, Estela. Produzir. In: FONSECA, T. M. G.; NASCIMENTO, M. L.; MARASCHIN, C. Pesquisar na diferença: um abecedário. Porto Alegre: Sulina, 2012.

22. SILVEIRA, Rosa Maria Hessel. A entrevista na pesquisa em educação: uma arena de significados. In: COSTA, Marisa Vorraber (Org.). Caminhos investigativos II: outros modos de pensar e fazer pesquisa em educação. Rio de Janeiro: Lamparina, 2007.

\section{Adir Casaro Nascimento}

Doutora em Educação Programa de Pós- Graduação em Educação - Mestrado e Doutorado Linha de pesquisa- Diversidade Cultural e Educação Indígena.

\section{Rozane Alonso Alves}

Doutora em Educação. Professora do Instituto Federal Goiano, Campus Avançado Ipameri.

\section{Como citar este documento:}

NASCIMENTO, Adir Casaro; ALVES, Rozane Alonso. Crianças indígenas e o campo dos estudos culturais: bricolar e experienciar como base metodológica. Reflexão e Ação, Santa Cruz do Sul, v. 26,
n.
3 ,
nov.
2018.
ISSN
1982-9949.
Disponível
em: 
<https://online.unisc.br/seer/index.php/reflex/article/view/12541>. Acesso em: 19 nov. 2018. doi:https://doi.org/10.17058/rea.v26i3.12541. 